\title{
CORRELATION BETWEEN COMPUTED TOMOGRAPHY SCAN FINDINGS AND FUNCTIONAL OUTCOME IN PATIENTS WITH ISCHAEMIC STROKE
}

\author{
Tamphaleima Khuraijam¹, Naorem Bimol'2, Nandabir Singh Yumnam³, Ningthemba Yumnam ${ }^{4}$, Taha Peya 5 , Shantibala Konjengbam ${ }^{6}$
}

${ }_{1}^{1}$ Postgraduate Trainee, Department of Physical Medicine and Rehabilitation, Regional Institute of Medical Sciences, Imphal. ${ }^{2}$ Assistant Professor, Department of Physical Medicine and Rehabilitation, Regional Institute of Medical Sciences, Imphal. 3 Professor, Department of Physical Medicine and Rehabilitation, Regional Institute of Medical Sciences, Imphal.

4 Postgraduate Trainee, Department of Physical Medicine and Rehabilitation, Regional Institute of Medical Sciences, Imphal.

5Postgraduate Trainee, Department of Physical Medicine and Rehabilitation, Regional Institute of Medical Sciences, Imphal. ${ }^{6}$ Associate Professor, Department Community Medicine, Regional Institute of Medical Sciences, Imphal.

\section{ABSTRACT}

\section{BACKGROUND}

Stroke is one of the leading causes of mortality and morbidity worldwide. Acute ischaemic strokes are the result of vascular occlusion secondary to thromboembolic disease and are more common than haemorrhagic stroke. Accurate prediction of motor recovery and functional outcome is difficult, but it is important for proper rehabilitative planning and post stroke care.

The objectives of this study is to determine the correlation between Computed Tomography (CT) scan findings and functional outcome in ischaemic stroke patients.

Study Design - Prospective cohort study.

Settings - Department of Physical Medicine and Rehabilitation, Regional Institute of Medical Sciences, Imphal, Manipur.

\section{MATERIALS AND METHODS}

All CT scan confirmed ischaemic stroke patients attending Department of PMR, RIMS, Imphal within 7 days of stroke onset, was included in the study. The stroke lesion size as recorded by CT was correlated with the functional outcome using FIM score on 7 , 30, 90 days post stroke.

\section{RESULTS}

A total of ninety patients were studied, 50 male and 40 female. Correlation between lesion size and FIM score at 7, 30 and 90 days were $r=-.566,-.671,-.604$ respectively. Regression analysis showed that the regression was significant $(F: 1,88)=41.542$; $\mathrm{p}=0.000$ ), which means that size of lesion can significantly predict the FIM score. The standardised regression coefficient for size of lesion was $b=-.566$, which was significant $(t=-6.445 ; p=0.000)$. There was thus a decrease in FIM score of .566 for an increase of $1 \mathrm{~mm}$ in size of lesion. The higher the standardised regression coefficient, $\mathrm{b}$ (in absolute terms) the better will be the prediction of the dependent variable. The R Square value indicates that $32 \%$ of the variance in FIM score can be explained by size of lesion.

\section{CONCLUSION}

It was thus concluded that there was a definite correlation between lesion size and functional outcome and CT scan findings can moderately predict functional outcome.

\section{KEYWORDS}

Correlation, CT Scan, Ischaemic Stroke, FIM Score.

HOW TO CITE THIS ARTICLE: Khuraijam T, Bimol N, Yumnam NS, et al. Correlation between computed tomography scan findings and functional outcome in patients with ischaemic stroke. J. Evolution Med. Dent. Sci. 2017;6(15):1179-1182, D0I: $10.14260 /$ Jemds/2017/257

\section{BACKGROUND \\ Stroke is one of the leading causes of mortality and morbidity worldwide. The WHO clinically defines stroke as "rapid development of clinical signs and symptoms of focal neurological deficit lasting more than $24 \mathrm{hrs}$. or leading to death with no apparent cause other than vascular origin."1 It can be broadly classified as Ischaemic (85\%) and Haemorrhagic (15\%). ${ }^{2}$ Acute ischaemic strokes are the result}

Financial or Other, Competing Interest: None.

Submission 12-01-2017, Peer Review 05-02-2017,

Acceptance 11-02-2017, Published 20-02-2017.

Corresponding Author:

Shantibala Konjengbam,

Department of Community Medicine

Regional Institute of Medical Sciences,

Imphal.

E-mail: shantibaladr@yahoo.com

bimoldr@yahoo.com

DOI: $10.14260 /$ jemds $/ 2017 / 257$

\section{(c) $(1)(-$}

of vascular occlusion secondary to thromboembolic disease and are more common than haemorrhagic stroke. ${ }^{3}$

Considering the high incidence and prevalence of stroke globally, understanding the disability following stroke, motor recovery pattern and prognostic indicators of recovery becomes important. As many as $88 \%$ of patients with acute stroke have hemiparesis. ${ }^{3}$ The incidence of dependence in activities of daily living immediately post stroke is highest and decreases significantly thereafter according to many authors. ${ }^{4}$ Some studies have shown that prognostic factors such as stroke severity, age and onset admission interval to be a relevant prognostic indicator in motor recovery and therefore functional outcome. ${ }^{5}$ NCCT is an integral component of assessment of patients with acute stroke.

Patient with large lesion after stroke are at greater risk of developing life-threatening complications. Lesion size as measured by CT has been used to prognosticate patient. 6 Several methods to measure infarct size on CT has been developed like manual tracing of infarct perimetry, pixel 
thresholding, stereological counting grid, measurement of three largest diameter and measurement of single largest diameter. ${ }^{7}$ Measurement of single largest diameter was used in this study. Limited studies have been done on lesion size and there are conflicting reports available. So this study was taken up to determine the correlation between CT scan findings and functional outcome in ischaemic stroke patients.

\section{MATERIALS AND METHODS}

The study was a prospective cohort study conducted in the Department of Physical Medicine and Rehabilitation, Regional Institute of Medical Sciences, Imphal, Manipur for a period of 2 years from $1^{\text {st }}$ September 2013 to $31^{\text {st }}$ August 2015. All CT confirmed ischaemic stroke patients attending Department of PMR, RIMS within 7 days of stroke onset fulfilling the inclusion criteria was included in the study.

\section{Inclusion Criteria}

1. First attack of ischaemic stroke confirmed by CT.

2. Patient with CT taken after 48 hours.

3. No other neurological disease.

4. Sufficient co-operation for clinical and neurologic testing.

5. Age 45 to 70 yrs.

\section{Exclusion Criteria}

1. Those who suffer from other neurological disorders.

2. Severely moribund patients.

3. Those who suffer from intracerebral haemorrhage.

FIM was assessed on 7, 30 and 90 days post stroke. CT lesion size of each patient were recorded and classified into three groups as $<15 \mathrm{~mm}, 15-30 \mathrm{~mm}$ and $>30 \mathrm{~mm}$.

\section{Outcome Measure}

Functional outcome was measured by using FIMS [Functional Independence Measure Score].

The FIMS consists of 18 items grouped into 6 subscales measuring self-care, sphincter control, transfer, locomotion, communication and social cognition ability. Each item is rated from 1 to 7 (score range: 18 to 126) based on the required level of assistance to perform the tasks (1 - complete assistance, 2 - maximal assistance, 3 - moderate assistance, 4 - minimal assistance, 5 - supervision, 6 - modified independence, 7 - complete independence). A low score on any subscale indicates a more severe disability. Evaluation of the reliability, validity and responsiveness of the FIM has been reported extensively. ${ }^{8}$ Initial assessment was done on 7 th day of stroke. Followup assessment was done on 30 and 90 days post stroke.

\section{Ethical Approval}

All the participants were informed about the nature of the study and those who agreed to participate were asked to sign the informed consent form. Participants were assured that they could withdraw from the study at any time. Prior approval of the Institutional Ethics Committee was taken.

\section{Data Analysis}

The data so collected was entered and analysed using the IBM SPSS version 16. Descriptive statistics like percentage, mean and standard deviation was used. ANOVA test was used to test the difference in FIM score between the different lesion sizes. Regression analysis was also used to determine how well stroke lesion size as measured by CT predicted functional outcome. A $\mathrm{P}$ value of $<0.05$ was taken as statistically significant.

\section{RESULTS}

A total of ninety patients were studied, 50 (55.6\%) males and $40(44.4 \%)$ females. The mean age of the patients was $58.26 \pm$ 7.021 years with age range from 45 to 70 years.

\begin{tabular}{|c|c|c|c|}
\hline $\begin{array}{c}\text { Size of } \\
\text { Lesion } \\
(\mathrm{mm})\end{array}$ & $\begin{array}{c}\text { Mean FIM } \\
\text { Score } \\
( \pm \text { SD) at } \\
\text { Baseline }\end{array}$ & $\begin{array}{c}\text { Mean FIM } \\
\text { Score }( \pm \text { SD) } \\
\text { at } 1^{\text {st }} \\
\text { Followup }\end{array}$ & $\begin{array}{c}\text { Mean FIM } \\
\text { Score ( } \pm \text { SD) } \\
\text { at } 2^{\text {nd }} \\
\text { Followup }\end{array}$ \\
\hline$<15$ & $53.93(15.4)$ & 76.33 (13.8) & $91.36(11.9)$ \\
\hline $15-30$ & $38.92(7.9)$ & $54.42(15.5)$ & $70.47(14.9$ \\
\hline$>30$ & $32.70(62.2)$ & $42.20(12.7)$ & $64.40(9.7)$ \\
\hline $\begin{array}{l}\text { F - value, } \\
P \text { - value }\end{array}$ & $36.612,0.000$ & $34.776,0.000$ & $32.742,0.000$ \\
\hline \multicolumn{4}{|c|}{$\begin{array}{l}\text { Table 1. Distribution of Mean FIM Scores at Baseline, } 1^{\text {st }} \\
\text { and } 2^{\text {nd }} \text { Followup by Size of Lesion }\end{array}$} \\
\hline
\end{tabular}

Table 1 shows that the mean FIM score was observed to be the highest when the size of lesion was $<15 \mathrm{~mm}$ at all followup periods. The mean FIM scores differed significantly between the different lesion sizes $(\mathrm{P}=0.000)$. Post Hoc test further revealed that there was significant difference in the mean FIM score between lesion sizes of $<15 \mathrm{~mm}$ and $15-30$ $\mathrm{mm}(\mathrm{P}=0.000)$ as well as between lesion sizes of $<15 \mathrm{~mm}$ and $>30 \mathrm{~mm}(\mathrm{P}=0.000)$. However, there was no significant difference in the FIM score between lesion sizes of $15-30$ $\mathrm{mm}$ and $>30 \mathrm{~mm}(\mathrm{P}=0.349)$ for all the three periods.

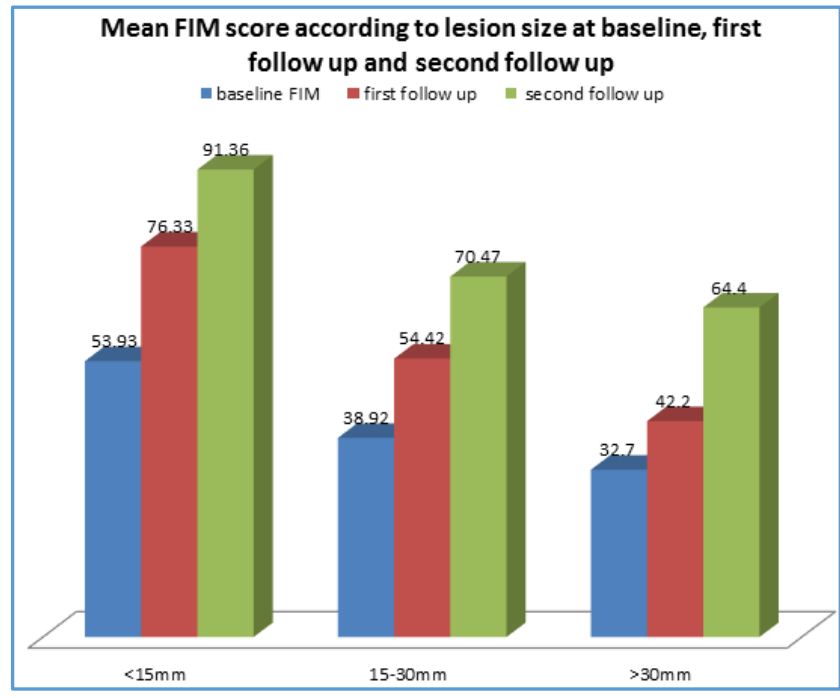

Figure 1. Mean FIM Scores at Baseline, First and Second Followup by Different Lesion Sizes

Figure 1 shows that the mean FIM scores increases in subsequent followups from baseline in all groups of patients with different lesion sizes. However, the gain in mean FIM score was highest (37.43) when lesion size was $<15 \mathrm{~mm}$ as compared to only 31.55 when lesion size was $15-30 \mathrm{~mm}$ and 31.7 when lesion size was $>30 \mathrm{~mm}$. 


\begin{tabular}{|c|c|c|c|}
\hline & $\begin{array}{c}\text { FIM Score at } \\
\text { Baseline }\end{array}$ & $\begin{array}{c}\text { FIM Score } \\
\text { at 1st Followup }\end{array}$ & $\begin{array}{c}\text { FIM Score at } \\
\text { 2nd Followup }\end{array}$ \\
\hline $\begin{array}{c}\text { Size of } \\
\text { Lesion }\end{array}$ & $-.566^{*}$ & $-.671^{*}$ & $-.604^{*}$ \\
\hline $\begin{array}{r}\text { Table 2. Pearson Correlation between Size of Lesion and } \\
\text { FIM Score at Baseline, 1 }{ }^{\text {st }} \text { and } 2^{\text {nd }} \text { Followup }\end{array}$ \\
\hline
\end{tabular}

$* \mathrm{P}<0.01$

Table 4 shows that there was significant correlation between size of lesion and FIM score indicating a negative relationship between the two variables.

\begin{tabular}{|c|c|c|c|c|c|}
\hline & $\mathbf{b}$ & $\begin{array}{c}\text { R Square } \\
\text { Change }\end{array}$ & F value & df & $\begin{array}{c}\text { Signifi- } \\
\text { cance }\end{array}$ \\
\hline $\begin{array}{c}\text { Size of lesion } \\
(\mathrm{mm})\end{array}$ & $\begin{array}{c}-566 \\
\text { Table 3. Prediction of FIM Score from Size of Lesion }\end{array}$ & 0.321 & 41.542 & 1,88 & 0.000 \\
\hline
\end{tabular}

Table 5 shows that the regression was significant (F:1,88) $=41.542 ; \mathrm{p}=0.000$ ), which means that size of lesion can significantly predict the FIM score. The standardised regression coefficient for size of lesion was $b=-.566$, which was significant $(\mathrm{t}=-6.445 ; \mathrm{p}=0.000)$. There was thus a decrease in FIM score of .566 for an increase of $1 \mathrm{~mm}$ in size of lesion. The higher the standardised regression coefficient, $\mathrm{b}$ (in absolute terms) the better will be the prediction of the dependent variable. The R square value indicates that $32 \%$ of the variance in FIM score can be explained by size of lesion.

\section{DISCUSSION}

In this study, we tried to find out if there was any association between CT scan findings taken in ischaemic stroke less than 7 days' duration and functional outcome in terms of FIM score at 30 days and 90 days. The predictive value of lesion size on functional outcome was also studied. All 90 patients who were enrolled completed the study. Non-Contrast CT scan being the initial mandatory investigation done in stroke patients, it was thus important to know the predictive value of CT findings.

It was observed that mean FIM score differed significantly at baseline, $1^{\text {st }}$ and $2^{\text {nd }}$ followup according to size of lesion. Lesion size of $<15 \mathrm{~mm}$ recorded the highest mean FIM score, while lesion size greater than $30 \mathrm{~mm}$ recorded lower mean FIM scores at baseline and also at subsequent followups. There was significant correlation between FIM score and lesion size in CT at baseline, $1^{\text {st }}$ and $2^{\text {nd }}$ followup with Pearson's correlation coefficient $r-.566,-.671$ and -.604 respectively. Correlation was strongest in the 1 st followup. This may be interpreted as gain in ADL activities was greatest at 30 days after stroke and it was significantly correlated with lesion size. Regression analysis was also significant with correlation coefficient of -.566. It was found that with increase in lesion size by $1 \mathrm{~mm}$, there will be decrease in FIM score by .566. Therefore, it can be inferred that lesion size can predict FIM score and $32 \%$ of the variance in FIM score can be explained by lesion size.

Some other studies had been conducted similar to this study. Brott et $\mathrm{al}^{6}$ found that neurological deficit at 7 days correlated highly with volume of infarct measured by CT at 7 - 10 days (Spearman's correlation coefficient, $r=.74$ ). Patient outcome at 3 months also correlated significantly with CT volume at 7 - 10 days. Neurological deficit present on admission also correlated strongly to lesion size at $7-10$ days.

Saver et $\mathrm{al}^{9}$ found that infarct volume correlated moderately with standard clinical measures of stroke outcome (Barthel Index, NIHSS, GOS). Several small series studies demonstrated no significant statistical correlation between CT lesion volume and clinical measures, while other larger series studies did show some correlation. ${ }^{8}$ But in this study, only FIM Score was used as an outcome measure.

$\mathrm{J} \mathrm{M}$ Wardlow et $\mathrm{al}^{10}$ found that radiological variables from the initial brain scan did not significantly improve the performance of outcome models derived from clinical variables. Radiological data added a little predictive information once the diagnosis of stroke was established.

Johnston $\mathrm{K} \mathrm{C}$ et al tried to identify risk model for outcome of ischaemic stroke and found that models that include both clinical and imaging variables (lesion size in CT) are statistically superior in performance to either alone. ${ }^{11}$ In another study, the same author found that CT infarct volume at 7 - 10 days as outcome predictor at 3 months performed less well compared to the NIHSS score at 1 week, which was highly predictive of 3 months clinical outcome in ischaemic stroke. ${ }^{12}$

Mohamed A et al found that infarct size positively influence stroke severity as shown by NIHSS score at 30 days. 13

The modest correlation between lesion size and outcome as observed in this study may be because besides lesion location and size, many confounding variables have not been taken into account. Inter individual variations in neuroplasticity and recovery capacity, variable exposure to pharmacological agents that secondarily enhance or inhibit neuroplasticity, degree of family support, variable development of medical complications of stroke including pneumonia, pulmonary emboli and deep vein thrombosis are some of the confounding variables.

There are many limitations in our study. Small sample size and older age above 70 not included in this study, even though incidence of ischaemic stroke was more common in above 65 yrs. CT scan lesion size was measured by measuring largest visible diameter. It was found in one study that even though measurement of largest diameter of infarct was the most rapid and reproducible and has good intra-observer and inter-observer variability the relation between largest diameter and their volume was insufficient. Another very important limitation in this study was the inclusion of all CT scan taken less than 7 days. The window period was too long taking into consideration of the fact that CT lesion demarcated more well with time.

\section{CONCLUSION}

This study aimed to find out up to what extent CT scan findings in ischaemic stroke can predict functional outcome at 30 days, 90 days post stroke. It was observed that there was a definite correlation between the two. But the correlation cannot be termed a strong one and there are many clinical variables, which plays a confounding role in predicting functional outcome in a patient of stroke. These clinical variables need to be taken into account, which may help in better prediction of functional outcome in ischaemic stroke. 


\section{REFERENCES}

[1] Taylor FC. Stroke in India. [1-13]. http://sancd.org/ uploads/pdf/factsheet Stroke pdf. 2012.

[2] Harvey RL, Roth EJ, Yu DT, et al. Stroke syndromes. In: Bradom RL. edr. Physical medicine and rehabilitation. $4^{\text {th }}$ edn. Philadelphia: Elsevier 2011:1177-222.

[3] Flores SC, Kulkarni R. Ishchemic stroke in emergency medicine.

2011. http//emedicine.medscape.com/article/19166852-

[4] Duncan PW. Stroke disability. Phs Ther 1994;74(5):399407.

[5] Paolucci S, Antonucci G, Grasso MG, et al. Functional outcome of ishchemic and hemorrhagic stroke patients after inpatient rehabilitation: a matched comparison. Stroke 2003;34(12):2861-5.

[6] Brott T, Marler JR, Olinger CP, et al. Measurement of acute cerebral infarction: lesion size by computed tomography. Stroke 1989;20(7):871-5.

[7] van der Worp HB, Claus SP, Bar PR, et al. Reproducibility of measurements of cerebral infarct volume on CT scans. Stroke 2001;32(2):424-30.
[8] Hsieh YW, Wu CY, Lin KC, et al. Responsiveness and validity of three outcome measures of motor function after stroke rehabilitation. Stroke 2009;40(4):1389-91.

[9] Saver JL, Johnstone KC, Homer D, et al. Infarct volume as a surrogate or auxiliary outcome measure in ischemic stroke clinical trials. The RANTTAS investigators. Stroke 1999;30(2):293-8.

[10] Wardlow JM, Lewis SC, Dennis MS, et al. Is visible infarction on computed tomography associated with an adverse prognosis in acute ischemic stroke? Stroke 1998;29(7):1315-9.

[11] Johnston KC, Connors AF, Wagner DP, et al. A predictive risk model for outcome of ischemic stroke. Stroke 2000;31(2):448-55.

[12] Johnston KC, Wagner DP, Haley EC, et al. Combined clinical and imaging information as an early stroke outcome measure. Stroke 2002;33(2):466-72.

[13] Abdelsalam M, Belal T, Hazen M, et al. Role of early CT in predicting recovery of ischemic stroke. Egypt J Neurol Psychiat Neurolsurg 2010;47(1):407-12. 